\title{
Tested In and Placed In: Are Sixth-Grade Boys and Girls Completing Early Challenge Math Coursework before They Are Ready?
}

\author{
David C. Hemphill ${ }^{1}$, John W. Hill ${ }^{2}$ \\ ${ }^{1}$ Millard Public Schools, Omaha, USA \\ ${ }^{2}$ Univertsity of Nebraska at Omaha, Omaha, USA \\ Email: jhill@unomaha.edu
}

Received June $9^{\text {th }}, 2013$; revised July $9^{\text {th }}, 2013$; accepted July $16^{\text {th }}, 2013$

\begin{abstract}
Copyright $(0) 2013$ David C. Hemphill, John W. Hill. This is an open access article distributed under the Creative Commons Attribution License, which permits unrestricted use, distribution, and reproduction in any medium, provided the original work is properly cited.
\end{abstract}

\begin{abstract}
The purpose of this study was to evaluate the algebra readiness outcomes of randomly selected sixth grade boys $(n=15)$ and girls $(n=15)$ who tested into and completed early challenge math coursework compared to the algebra readiness outcomes of randomly selected same school sixth grade boys $(n=15)$ and girls $(n=15)$ who tested below the admission threshold but were placed into and completed early challenge math coursework based on teachers' recommendations to determine if these students, both tested in and placed in, were enrolled into higher-level math courses before they were ready-a growing concern nationwide. Orleans Hanna Algebra Prognosis Test scores were analyzed using dependent $t$ tests to determine sixth-grade pretest-posttest within group progress and Orleans Hanna Algebra Prognosis Test scores were analyzed using Analysis of Covariance for between group statistical comparison across gender and placement conditions to determine rate of test score improvement. Between group challenge math end of sixth-grade report card grade scores were analyzed using Analysis of Variance, also across gender and placement conditions. Taken all together the study test scores and grade results clearly indicate that boys and girls whether tested into or placed into sixth-grade challenge math coursework based on teacher recommendations were equally prepared and ready for seventh-grade pre-algebra studies following a year of early challenge math. Finally, we assert that placement criteria and procedures will continue to predict student success where there are, in combination, a well-designed rigorous math curriculum, committed, caring, and skilled teachers, and motivated students - making early challenge math coursework placement the only appropriate option for students when these conditions are extant.
\end{abstract}

Keywords: Algebra Readiness; Challenge Math; Sixth Grade Students; Tested In; Placed In

\section{Introduction}

Over the past two decades there has been a push to offer algebra coursework earlier and earlier to all elementary and middle school students (Dulaney, 1996; Fensterwald, 2010; Steen, 1999). Currently, the goal of algebra for all mathematics policy in the United States is to provide early math experiences that will prepare students for the more formal study of algebra in high school (NCTM, 2000; Rivera, 2006). However, it is not clear what early algebra experiences should be and whether or not these early abstract math experiences will result in improved advanced math achievement for all students (Knuth et al., 2005; Schmidt, 2004; US Department of Education, 2008). The push to have all middle school students complete math before they are ready has resulted in what Bracey (2008) has referred to as the great algebra hoax in California, where it has recently been determined that nearly 120,000 eighth-grade students, currently taking algebra, have math ability scores measured at the second-grade level. Algebra, as recently as the 1990s, was considered a class for gifted math students. By 2007, 31\% of all students in the eighth-grade nationally were taking algebra.
The push for accelerated algebra courses in the middle school years is motivated, at least in part, by the results of the math scores of students in the United States compared to students internationally on the Trends in International Mathematics and Science Study (TIMSS, 1999). In the TIMSS report United States students in the fourth-grade ranked 12th out of 26 nations, eighth-grade students ranked 28th out of 41 nations, and 12-grade students ranked 19th out of 21 nations on the math examination covering content and cognitive dimensions. On the Program for International Student Assessment (PISA) test completed in 2006, United States 15-year-old students' average math score was lower than the Organization for Economic Co-operation and Development (OECD) student average score. United States students averaged 474 and the OECD average was 498. This placed the United States students in the bottom quarter when compared with other participating nations (US Department of Education, 2010).

Low scores on international measures often result in government mandates for sweeping reform in educational practices often dissociated from the real-world needs and abilities of students (Board, 2010; Guttenplan, 2010). Unfortunately, a stu- 
dent who is misplaced in a more rigorous math class without the automatic basic skills need to complete and solve more complex problems may only learn failure (GreatSchools, 2010; Stacey, 2009). The National Assessment of Education Progress (NAEP) data suggests that the effort to push more kids into algebra math classes before students are ready is an unfortunate national trend. While lower achieving students only accounted for $8 \%$ of the students in higher-level math classes in 2000 by 2005 the number taking higher-level math courses rose to 28.6\% (Lee, Grigg, \& Dion, 2007; Loveless, 2008). California is leading the charge for algebra for all eighth-grade students. From 2003-2008, students taking algebra increased 63\%. However, only $42 \%$ of those taking algebra scored proficient on the state algebra test. A study found that large numbers of eighth-grade students are retaking algebra in ninth-grade and doing worse the second time through the course (Fensterwald, 2010).

Students who take algebra before they have a strong foundation in basic math and have the mental development may find themselves unprepared for college or the work force. Students that are not prepared usually have to relearn math in a remedial class later which can hurt students chances for success when compared with students who are prepared for algebra and were enrolled in algebra when they were ready (GreatSchools, 2010; Steen, 1992; Steen, 1999).

\section{Review of Literature}

\section{Algebra throughout the K-12 Curriculum}

There is a real effort to include problem solving and mathematical investigation into our students' current challenge math curriculum (National Council of Teachers of Mathematics, 2002). This concerted effort to bolster our math curriculum, no doubt comes from reports such as the Program for International Student Assessment (PISA) as reported by the US Department of Education (2010). In the introduction of this document, data were given to show the United States poor performance when compared to other nations. A closer look at that data shows that PISA describes six mathematics literacy proficiency levels ranging from 1 to 6 , the later being the most advanced. Twentyseven percent of US students scored at or above level 4 (above proficiency). This is lower than the other $32 \%$ of students in OECD countries on average that scored at or above level 4 . According to the study level 4 students are able to complete higher order tasks like solving problems involving visual or spatial reasoning in unfamiliar contexts. While these results are not terrible, what is concerning is that nearly one-quarter of United States students scored below level 2 indicating they are not able to consistently use basic computational skills to draw accurate conclusions regarding problems in real-life situations (US Department of Education, 2010).

\section{“Algebrafying” the K-12 Curriculum}

Algebra has always acted as the gateway class to all higherlevel math courses (McCoy, 2005). However, for some, algebra is the reform gateway to K-12 math curriculum for the next century. To some it is thought that the key to this algebra reform is integrating algebra across the K-12 math curriculum (Katz, 2007; Kaput, 2000). Kaput (2000) refers to algebra in two ways; "algebra the institution" and "algebra the web of knowledge and skill" (p. 2). For many it is claimed that algebra for all is the charge of this institution. As Kaput states, "But this algebra is the disease for which it purports to be the cure!" It is this "algebra the web of knowledge and skill" that is needed in the math classrooms of today. When we think about including algebra into earlier and earlier grades, it is not the "algebra institution" we are referring too but the "algebra the web of knowledge and skill" in which we intend to transform mathematics curriculum (Kaput, 2000). In much of the research that falls into math or algebra curriculum reform we find less talk about the X's and Y's and more discussion of the connections, thought processes, and generalizations that can come from studying math concepts at a deeper level. Early algebra is an approach to educating students in the early grades that explore the deeper meanings of mathematics. It includes two foci: (1) generalizing, identifying, expressing, and justifying math structure, properties, and relationships and (2) reasoning and actions based on the forms of generalizations (Katz, 2007). According to many, early algebra is not a curriculum addition. It is not thought to be a separate list of activities or lessons that should be taught after the students have been taught math computation skills. As soon as students in elementary school are able to count and use math symbols, early algebra should be embedded in the math lessons being taught (VanNoy, 2010). It is also believed that early algebra is a way to bring depth of understanding to the mathematics understanding of young children by digging deeper into the concepts being taught so that students can generalize relationships and properties of those concepts. Early algebra is not a "moving to earlier grade levels" of algebra skills that are usually taught in middle school as a pre-algebra class. The goals of early algebra are for students to learn to reason algebraically as they begin to acquire the ideas behind symbolic algebraic language and explore math situations that draw on students' mathematical knowledge in order to reflect, build arguments, and justify new ideas (Katz, 2007).

\section{Gender Issues and Mathematics}

There has been a great deal of research over gender differences in math abilities. Much research focuses on the underrepresentation of women in the area of math and science (ElseQuest, Hyde, \& Linn, 2010; Halpern et al., 2007; Hyde, Fennama, \& Lamon, 1990; Penner, 2008; Valentine, 1998). Scores from the 2009 PISA show that 15-year-old boys outperformed girl classmates by 20 points in overall math proficiency (NASSP 2011). However, when looking at the results of the National Assessment of Educational Progress over the last ten years, the reported gap between boys and girls is $2 \%$ (Geist \& King, 2008). A closer look at NAEP data reveals that while girls do equally as well as boys and have made gains in math more recently, there is a difference in moderately complex procedures and reasoning for 13-year-olds. Boys are more proficient in this area, outperforming girls, $32.6 \%$ proficient to $25.6 \%$ proficient. When comparing 17 -year-olds, boys are $8.8 \%$ proficient on multi-step problem solving and algebra compared to girls at $5.1 \%$ (James, 2007).

Women have had great success in college. American women receive more college degrees than men every year, a trend that began in 1982, and continues to grow today. Even with these successes, females score significantly lower on many high stakes standardized tests, including the verbal and mathematics section of both the Scholastic Aptitude Test (SAT) and the Graduate Record Examination (GRE) (Halpern et al., 2007). 
Females also score lower on mathematics tests that do not closely resemble the material that was taught in school, despite earning higher grades than males in school (Halpern, 2007; Willingham \& Cole, 1997).

In a meta-analysis study of gender differences in math performance it was learned that there has been gender differences in math performance for years and that those differences are still with us today. Conclusions around the world tend to suggest simply that males outscore females on math tests. A closer look at the research reveals that the difference is not visible in early childhood, but becomes more prevalent during adolescents. It is thought that boys are better able to handle more complex problem solving and girls favor the less complex computation tasks (Hyde, Fennema, \& Lamon, 1990).

\section{Biological and Social Factors in Early Mathematics Achievement}

In research there appear to be two themes that come to surface as you look at gender difference in mathematics; biological and social factors. At first glance there may not appear to be much difference in the male and female brain, but a much closer look is needed to notice the difference between males and females. Through magnetic resonance imaging (MRI), scientist, have been able to learn a great deal about the differences of the brain between genders. The cerebral cortex is thicker on the right side in men and thicker on the left side in women. This indicates that the thicker side of the brain is more developed than the opposite side of the brain. The hemispheres of a female's brain will appear to be more identical where a male's brain is asymmetrical (Halpern, 2000). This difference means that a female will process spatial abilities in both hemispheres while males use one hemisphere (Penner, 2008) — a fact evidenced in research of damaged brains by Gazzaniga, Ivry, \& Magnum (as cited in Penner, 2008). Furthermore, males with damaged left hemispheres show a loss of verbal abilities and damaged right hemispheres experience a loss of spatial abilities. Females with damage to the left hemisphere see a decrease in spatial and verbal abilities but no apparent decrease is found with damage to the right hemisphere in females. Males have larger inferior parietal lobes so they are better at judging speed, estimating time, and rotating objects mentally. In fact, at very early ages, boys perform better than girls in this area, in many cases by close to a full standard deviation (Halpern, 2004). In a meta-analysis study of gender differences in math, data from the content domain of Space/Shape on the PISA, an area that measures understanding of spatial relationships, showed boys were slightly favored in this content area albeit with a low effect size of ( $d=0.15$; Else-Quest, Hyde, \& Linn, 2010).

However, girls are better at retrieving information from long-term memory and typically score better than boys on tests of verbal learning and the creation and understanding of complex prose (Halpern, 2004). Male brains seem to be more specialized overall, whereas female brains seem to be more multipurpose. This brain difference is apparent in elementary school when math involves math facts, calculations, and the quick retrieval similar to that needed in language generation and understanding favor girls. In algebra, girls perform better on problems where the solution involves a process similar to those of language processing (Gallagher, Levin, \& Cahalan, 2002; Hyde, Fennama, \& Lamon, 1990).

Another area of biological difference between males and fe- males is the developmental process. Magnetic Resonance Imaging and Electro Encephalograph scans of male and female brains have given us images that show the brain of a 17-yearold boy are equivalent to the brain of an 11-year-old girl. Another way of measuring brain maturation is to look at the degree of myelination. Myelin, necessary for fast, clear nerve impulse transmission, is a waxy material that coats the axons in the brain. An infant will have no myelin and by adulthood the brain will be full of the substance. Using this substance scientist show a three to four year gap in brain development between boys and girls. Males did not catch up to females until the age of 29 (Gallagher et al., 2002).

We know that there are developmental difference in the brains and bodies of our children, but research is also trying to assess how much impact social factors play into the mathematics learning of our boys and girls. In July of 1992, a talking Barbie hit the shelves of stores and much to the public's dismay uttered the phrase, "math class is tough." According to Sax (2010) and Geist and King (2008) research shows that girls feel less confident in their ability to perform well on math tests while boys often show greater confidence or over-confidence in their abilities. Kloosterman, Tassell, Ponniah, and Essex (2008) found that most students, seventh through 12th-grade, believed that math is a gender-neutral domain but female students were stronger in those beliefs than males. Boys who rated themselves as good or excellent in math felt more strongly that math is not a female domain. Another study showed that students', when asked to nominate who is best in their class in language arts and math, named boys and girls equally in language arts, but in math the boys nominated only boys and the girls started nominating more boys than girls from the fourth-grade on (Räty, Kasanen, Kiiskinen, \& Nykky, 2004).

Social factors are also determined by parent influence. For example, in research by Leedy, LaLonde, and Runk in 2003 (as cited in Geist \& King, 2008) parents of sons tend to expect their sons to learn math skills earlier than do parents of girls and as the children get older they expect their daughters to work hard to get good grades in math while parents of boys emphasize the learning of math. Regardless of the gender, higher levels of parental involvement with their children's education equates to higher levels of performance in mathematics (Muller, 1998). According to a meta-analysis study by Lytton and Romney in 1991 (as cited by Halpern et al., 2007) there was no significant difference in how parents treated males and females in encouraging achievement but this study did not differentiate the different areas of study, for example language arts or mathematics. Furthermore, boys tend to gain more spatial experience because they tend to be allowed to roam over a greater area than girls who chose activities that are closer to home. This roaming of the neighborhood allows boys to have a better spatial understanding of the area as represented on drawings of maps between boys and girls (Halpern et al., 2007). This influence is an extension of the parent influence but is reinforced throughout the neighborhood as parents in the neighborhood allow boys more freedom to venture further from home.

\section{Admission Standards for Early Algebra Course Participation}

Understanding biological and social factors, math curriculum, and the readiness of students for taking algebra is important, but of equal importance is having an effective placement proc- 
ess to enroll students into the correct math courses. The placement process should help place a student on a path for mathematics success throughout the middle school experience and into high school. Bracey (2008) and Loveless (2008) assert that algebra once was a class for gifted students but now has become a class that all students must take, whether they are ready or not. For example in the research school district during the 2008-2009 school year 144 students, $43 \%$ of the total eighthgrade population, were taking algebra as eighth-graders. There were also 19 seventh-grade students that were taking algebra during their seventh-grade year. In a check of enrollment numbers for algebra in 2005-2006, there were only 82 students taking algebra. This is a trend that appears to be growing in the research school as well as nationally.

In this study the current method of selecting students into challenge math used a triangulated composite score based on the pre-sixth-grade Orleans-Hanna test score, the fourth-grade Terra Nova math composite test score, and the school districts math Essential Learner Outcome (ELO) test score. These three scores are scaled to 15 points with each component sharing an equal part in the 15 points. Students with higher scores are placed in Challenge Math 6 and students below the cut score are recommended for Math 6 to prepare for more challenging math coursework in the seventh-grade. Students who scores are 35 or higher - up to 50 points - bypass the process of selection into challenge math and are placed in pre-algebra for sixthgrade. If students score less than 35 raw score points on the Orleans-Hanna, then the triangulation of scores is used. If a student is on the bubble between being placed in Math 6 or Challenge Math, the student's fifth-grade teacher, is contacted by the middle school registrar in order to give his/her input on the best math placement. This recommendation involves the fifth-grade teacher making a decision for each student based on the knowledge that he/she was on the bubble for placement in Math 6 or Challenge Math 6. Fifth-grade teachers are not given detailed Orleans-Hanna scores to assist in their placement decisions.

\section{Early Algebra Placement}

It appears that over the past two decades a growing trend of placing more and more students in algebra at earlier grades may be becoming the norm. This relatively new norm has potentially devastating consequences if not handled appropriately. Educators cannot take existing algebra curriculum and push it into lower grade levels and expect that all students will be successful. As previously mentioned, algebra is a gateway course. A successful completion of algebra opens more opportunities for students. These students are able to complete more advanced coursework in mathematics and pursue the studies of more advanced careers such as, engineering and the medical field. Algebra for all is a noble educational goal, but it is not a realistic goal when attempting to do so at the eighth-grade level. Not all students are ready for the abstract thinking involved in understanding algebraic concepts. However, government officials see algebra as the way to put the United States on top in the global assessment race. Parents see algebra as a rigorous course to push their child, while others see it as a key to a lucrative career (Steen, 1999). All educators need to ask some practical questions: First, Are all students ready for algebra? Secondly, is our mathematics curriculum getting students ready for algebra? And finally, what is the rush to get to algebra? The answers to these questions are the key to providing quality, student ready mathematics programs.

\section{Methodology}

\section{Purpose of the Study}

The purpose of this study was to evaluate the algebra readiness outcomes of randomly selected sixth grade boys and girls who tested into and completed early challenge math coursework compared to the algebra readiness outcomes of randomly selected same school sixth grade boys and girls who tested below the admission threshold but were placed into and completed early challenge math coursework based on teachers' recommendations to determine if these students, both tested in and placed in, were enrolled into higher-level math courses before they were ready.

\section{Student Participant Demographics}

This study included a randomly selected group of students ( $n$ $=30$ ) who met the measured test score criteria for challenge math placement and a randomly selected group of students $(n=$ 30 ), who did not meet the measured test score criteria for challenge math placement but received challenge math based on fifth-grade teachers' recommendations. These students were randomly selected from a total of 102 same school sixth-grade students with the same placement and gender conditions. Of the total number of selected subjects who met the measured test score criteria for challenge math placement $(N=60), 15(50 \%)$ were boys and $15(50 \%)$ were girls. Of the total number of selected subjects who did not meet the measured test score criteria for challenge math placement but received challenge math based on teacher recommendation $15(50 \%)$ were boys and $15(50 \%)$ were girls. Of the total number of selected subjects who met the measured test score criteria for challenge math placement $(n=30) 30(100 \%)$ were White. Of the total number of selected subjects who did not meet the measured test score criteria for challenge math placement but received challenge math based on teacher or parent recommendation $(n=30)$ $26(86.6 \%)$ were White, $3(10 \%)$ were Asian, 1 (3.3\%) was African-American. The age range for all study participants was from 10 years to 12 years.

\section{Math Achievement Dependent Measures}

The study analyzed math achievement as measured by students' pretest and posttest (a) Orleans Hanna Algebra Prognosis Test scores (Ciechalski, 2005; Daubert, 2006; Kuchemann \& Secolsky, 1985; Toone, 2011) and (b) students' final posttest challenge math report card grade scores.

\section{Implementation of the Independent Variables}

The independent variables for this study were sixth-grade boys and girls meeting measured test score criteria for challenge math placement compared to sixth-grade boys and girls not meeting measured test score criteria for challenge math placement but receiving challenge math placement based on teacher recommendation. These groups comprise the four research arms of the study. All groups of students were randomly selected from the same student population and were in attendance at the same research middle school throughout the study. 


\section{Research Questions}

The following three research questions guided the study comparing within group and between group algebra prognosis test scores and between group challenge math report card grade scores for the gender and placement conditions.

1) Do sixth-grade Boys Tested In, or sixth-grade Girls Tested In, or sixth-grade Boys Placed In, or sixth-grade Girls Placed In lose, maintain, or improve their end of school year pretest fifthgrade Orleans Hanna Algebra Prognosis test scores compared to their end of school year posttest sixth-grade Orleans Hanna Algebra Prognosis test scores?

2) Do sixth-grade Boys Tested In, or sixth-grade Girls Tested In, or sixth-grade Boys Placed In, or sixth-grade Girls Placed In have congruent or different posttest end of school year sixthgrade rate of gain or loss Orleans Hanna Algebra Prognosis test scores?

3) Do sixth-grade Boys Tested In, or sixth-grade Girls Tested In, or sixth-grade Boys Placed In, or sixth-grade Girls Placed In have congruent or different posttest end of school year sixthgrade final challenge math report card grade scores?

\section{Assumptions and Limitations of the Study}

The study has several strong features including: (a) district wide assessment process is used for placing students in middle school math classes, (b) the challenge math program is an established and widely respected course option, (c) all subjects were enrolled in the same school district during the study and were in the same school within the district during the sixthgrade year, (d) students placed in the challenge math class were taught the same district math curriculum, and (e) all students were assessed by the same standardized prognosis test. The exploratory study was confined to sixth-grade students $(N=60)$ participating in a yearlong challenge math course. The small number of study subjects could limit the utility and generalizability of the study results and findings. Permission from the appropriate school research personnel and University of Nebraska Medical Center/University of Nebraska at Omaha Joint Institutional Review Board for the Protection of Human Subjects approval was granted for the study before data were collected and analyzed.

\section{Results}

The first pretest-posttest hypothesis was tested using the dependent $t$ test. Null hypotheses for Orleans-Hanna Algebra Prognosis Test score improvement over time were rejected for the end of fifth-grade pretest compared to ending sixth-grade posttest for all four groups where Boys Tested In, pretest $M=$ 23.20, $S D=4.89$, posttest $M=38.07, S D=6.65 ; t(14)=7.13, p$ $<.001$ (one-tailed), ES $=1.867$, Girls Tested In, pretest $M=$ 21.20, $S D=4.81$, posttest $M=36.33, S D=9.96, t(14)=9.87, p$ $<.001$ (one-tailed), $\mathrm{ES}=2.686$, Boys Placed In, pretest $M=$ $18.60, S D=4.91$, posttest $M=34.80, S D=10.04, t(14)=6.86$, $p<.001$ (one-tailed), $\mathrm{ES}=2.010$, and Girls Placed In, pretest $M$ $=20.87, S D=4.31$, posttest $M=35.93, S D=6.40, t(14)=7.94$, $p<.001$ (one-tailed), $\mathrm{ES}=2.099$.

The second posttest-posttest hypothesis was tested using Analysis of Covariance (ANCOVA) with the pretest mean scores serving as the concomitant variable and the posttest scores as the dependent variable. The null hypothesis was not rejected for the posttest Orleans-Hanna Algebra Prognosis Test
ANCOVA results between group comparison for Boys Tested In, (posttest $M=38.07, S D=6.65$; ANCOVA adjusted posttest $M=36.99$ ), Girls Tested In (posttest $M=36.33, S D=9.96$; ANCOVA adjusted posttest $M=36.22$ ), Boys Placed In (posttest $M=34.80, S D=10.04$; ANCOVA adjusted posttest $M=$ 35.93), and Girls Placed In (posttest $M=35.93, S D=6.40$; ANCOVA adjusted posttest $M=35.98$ ), indicating rate of test score improvement equipoise for all placement and gender conditions where $(F(3,55)=0.06, p=.98)$. Because no significant main effect was found post hoc, contrast analyses were not conducted.

The third posttest-posttest hypothesis was tested using Analysis of Variance (ANOVA). The null hypothesis was not rejected for the last trimester sixth-grade posttest challenge math course grade score posttest-posttest ANOVA results be- tween group comparison for Boys Tested In $(M=92.25, S D=4.40)$, Girls Tested In $(M=93.75, S D=4.52)$, Boys Placed In $(M=$ 91.13, $S D=5.12)$ and Girls Placed In $(M=93.54, S D=3.11)$, where $(F(3,56)=1.18, p=.32)$. Because no significant main effect was found post hoc, contrast analyses were not conducted.

\section{Conclusion}

Based on the results the following conclusions may be drawn from the study for each of the three research questions.

Overall Orleans-Hanna Algebra Prognosis Test posttest compared to pretest mean score change across gender and placement conditions, all in the direction of statistically improved scores over time, validates gender and challenge math coursework placement readiness for these students where Boys Tested In posttest Orleans-Hanna Algebra Prognosis Test score of 38.07 was +14.87 points greater than pretest, Girls Tested In posttest Orleans-Hanna Algebra Prognosis Test score of 36.33 was +15.13 points greater than pretest, Boys Placed In posttest Orleans-Hanna Algebra Prognosis Test score of 34.80 was +16.20 points greater than pretest, and Girls Placed In posttest Orleans-Hanna Algebra Prognosis Test score of 35.93 was +15.06 points greater than pretest. These scores represent an enviable pattern of math test score improvement across time from the end of the fifth-grade to the end of the sixth-grade for these students across gender and placement conditions.

It is gratifying than that overall posttest compared to posttest ANCOVA results for ending sixth-grade Orleans-Hanna Algebra Prognosis Test scores for sixth-grade boys meeting measured test score criteria for challenge math placement, sixthgrade girls meeting measured test score criteria for challenge math placement, sixth-grade boys not meeting measured test score criteria for challenge math placement but placed into challenge math based on teacher recommendation, and sixthgrade girls not meeting measured test score criteria for challenge math placement but placed into challenge math based on teacher recommendation were found to be congruent indicating rate of test score improvement equipoise across placement and gender conditions - again validating challenge math coursework placement readiness for these students. Moreover, mean posttest Orleans-Hanna Algebra Prognosis Test scores across placement and gender conditions were measured just below or above the research school districts cut score of 35 required for automatic early placement into pre-algebra classes where Boys Tested In posttest Orleans-Hanna Algebra Prognosis Test score of 38.07 was +3.07 points above the cut score, Girls Tested In 
posttest Orleans-Hanna Algebra Prognosis Test score of 36.33 was +1.33 points above the cut score, Boys Placed In posttest Orleans-Hanna Algebra Prognosis Test score of 34.80 was -0.20 points below the cut score, and Girls Placed In posttest Orleans-Hanna Algebra Prognosis Test score of 35.93 was +0.93 points above the cut score.

Finally, converting the posttest-posttest between group analysis of variance last trimester sixth-grade posttest challenge math classroom performance results into grade nomenclature helps put these students' results in perspective where sixthgrade boys meeting measured test score criteria for placement into challenge math mean score result of 92.25 , was the equivalent of a grade of "B" or excellent math class performance, sixth-grade girls meeting measured test score criteria for placement into challenge math mean score of 93.75 , was the equivalent of a grade of " $\mathrm{A}$ " or outstanding math class performance, sixth-grade boys not meeting measured test score criteria placed into challenge math based on teacher recommendation mean score of 91.13, was the equivalent of a grade of "B" or excellent math class performance, and sixth-grade girls not meeting measured test score criteria placed into challenge math based on teacher recommendation mean score of 93.54, was the equivalent of a grade of a "A" or outstanding math class performance. This overall excellent to outstanding classroom performance is consistent with the significant within group posttest compared to pretest score improvement found in the first research question and the rate of test score improvement equipoise noted in the second research question analysis. Furthermore, as with the second analysis no statistically significant variance was found between students regardless of placement and gender conditions. Taken all together the study test scores and grade results clearly indicate that whether tested in or placed in to challenge math coursework based on teacher recommendations these boys and girls were equally prepared and ready for seventh-grade pre-algebra studies following a year of early challenge math.

\section{Discussion}

The practice used by the research school in testing and then placing students based on the results of these tests, and in some cases teacher recommendations, appears to be working effectively based on the results of this study - that is boys and girls were not being placed into early challenge math coursework before they were ready. It should be noted that students who attended the research school and were participants in this study were mostly from higher socio-economic homes with collegeeducated parents who set high educational expectations for their children. Therefore, the study subjects were fortunate enough to have education role models in front of them each day and were being raised in what has been referred to as a concerted cultivation manner that implies focus on the importance of learning, education, achievement, and service to others based on learning success (Lareau, 2003). However, the research school district is a member of a two county, 11 school district learning community required by state statute to provide education to students from families with fewer economic advantages. Studies show that students from families with fewer economic advantages perform less well than their peers from more socio-economically advantaged homes (Baharudin \& Luster, 1998; Jeynes, 2002; Eamon, 2005; Majoribanks, 1996; Hochschild, 2003; McNeal, 2001; Seyfried, 1998). Because the research school district will be enrolling increasing numbers of students from lower socio-economic circumstances in response to the economic diversity mandate of the aforementioned 11 school district learning community legislation it will be important that the research school make every effort to place these students in Challenge Math 6 classes using both test results and teacher recommendations in consultation with the students parents.

\section{Final Thought}

Students that take challenge math in sixth-grade are on a math track for placement in pre-algebra in seventh-grade and then placement in algebra in eighth-grade. While all groups in this study performed well during the sixth-grade year taking challenge math, it is not known how these students will perform throughout the remainder of their middle school and high school math studies. The premise of this study is that students are being pushed into higher-level math courses before they are ready, therefore, additional research must be conducted to follow these challenge math students who tested in to or were placed in to early challenge math coursework based on teacher recommendation in a longitudinal study to evaluate progress in later math courses. Because the importance of math cannot be overstated for all, boys and girls alike, who seek to complete advanced education leading to careers of service to others, it is imperative that all schools provide challenging and engaging math instruction as a priority for all students regardless of their current level of math ability. Finally, we assert that placement criteria and procedures will continue to predict student success where there are, in combination, a well-designed rigorous math curriculum, committed, caring, and skilled teachers, and motivated students - making early challenge math coursework placement the only appropriate option for students when these conditions are extant.

\section{REFERENCES}

Baharudin, R., \& Luster, T. (1998). Factors related to the quality of the home environment and children's achievement. Journal of Family Issues, 19, 375-403. doi:10.1177/019251398019004002

Board, J. (2010). Criticism of public education-Inequality of opportunity, highly bureaucratic systems, achievement-based outcomes, school choice, reform after reform.

http://education.stateuniversity.com/pages/2341/Public-Education-Cr iticism.html

Bracey, G. W. (2008). The algebra hoax. Phi Delta Kappan, 90, 306307.

Ciechalski, J. C. (2005). Review of the Orleans-Hanna algebra prognosis test (3rd ed.). Greenville, NC: Professor, East Carolina University.

Daubert, H. (2006). Millard investigation: Conversation with peggy brendel. Omaha, NE: Millard Public Schools.

Dulaney, C. (1996). Should students take algebra I in middle school? E\&R Report, 96(.08), Raleigh, NC: Eye on Evaluation-Evaluation and Research Department: Wake County Public School System.

Eamon, M. K. (2005). Social-demographic, school, neighborhood, and parenting influences on academic achievement of Latino young adolescents. Journal of Youth and Adolescence, 34, 163-175. doi:10.1007/s10964-005-3214-X

Else-Quest, N. M., Hyde, J., \& Linn, M. C. (2010). Cross-national patterns of gender differences in mathematics: A meta-analysis. Psychological Bulletin, 136, 103-127. doi:10.1037/a0018053

Fensterwald, J. (2010). Too many students forced to retake algebra. Thoughts on public education: Analysis, opinions and ruminations on California education policy. Silicon Valley Education Foundation. 
http://toped.svefoundation.org/2010/03/24/too-many-students-forced -to-retake-algebra/

Gallagher, A., Levin, J., \& Cahalan, C. (2002). GRE research: Cognitive patterns of gender differences on mathematics admissions tests (ETS Report No. 02-19). Princeton, NJ: Educational Testing Service.

Geist, E. A., \& King, M. (2008). Different, not better: Gender differences in mathematics learning and achievement. Journal of Instructional Psychology, 35, 43-52.

GreatSchools: Involved Parents. Successful Kids (2010). Why is algebra so important? Algebra is known as a gatekeeper subject, so when should your child take it?

http://www.greatschools.org/students/academic-skills/why-algebra.gs ?content $=354$

Guttenplan, D. D. (2010). Western nations react to poor education results. The New York Times.

http://www.nytimes.com/2010/12/09/world/europe/09education.html

Halpern, D. F. (2000). Sex differences in cognitive abilities. Mahwah, N.J.: Lawrence Erlbaum Associates.

Halpern, D. F. (2004). A cognitive-process taxonomy for sex differences in cognitive abilities. American Psychological Society, 13, 135-139.

Halpern, D. F., Benbow, C. P., Geary, D. C., Gur, R. C., Hyde, J. S., \& Gernsbacher, M. A. (2007). The science of sex differences in science and mathematics. Association for Psychological Science, 8, 1-51.

Hochschild, J. L. (2003). Social class in public schools. Journal of Social Issues, 59, 821-840. doi:10.1046/j.0022-4537.2003.00092.x

Hyde, J. S., Fennama, E., \& Lamon, S. L. (1990). Gender differences in mathematics performance: A meta-analysis. Psychological Bulletin, 107, 139-155. doi:10.1037/0033-2909.107.2.139

James, A. N. (2007). Gender differences and the teaching of mathematics. Inquiry, 12, 14-25.

Jeynes, W. H. (2002). Examining the effects of parental absence on the academic achievement of adolescents: The challenge of controlling for family income. Journal of Family and Economic Issues, 23, 189210. doi:10.1023/A:1015790701554

Kaput, J. K. (2000). Transforming algebra from an engine of inequity to an engine of mathematical power by "algebrafying" the K-12 curriculum. Dartmouth, MA: National Center for Improving Student Learning and Achievement in Mathematics and Science.

Katz, V. J. (2007). Algebra: Gateway to a technological future. The Mathematical Association of America (MAA).

http://www.maa.org/algebra-report/Algebra-Gateway-Tech-Future.pdf

Kloosterman, P., Tassell, J., Ponniah, A. G., \& Essex, N. K. (2008). Perceptions of mathematics and gender. School Science and Mathematics, 108, 149-162. doi:10.1111/j.1949-8594.2008.tb17821.x

Knuth, E. J., Alibali, M. W., McNeil, N. M., Weinberg, A., \& Stephens, A. C. (2005). Middle school students' understanding of core algebraic concepts: Equivalence \& Variable. International Journal on Mathematics Education (ZDM), 37, 68-76. doi:10.1007/BF02655899

Kuchemann, D., \& Secolsky, C. (1985). Review of the Orleans Hanna prognosis test. In J. V. Mitchell Jr. (Ed.), The ninth mental measurement yearbook (pp. 1105-1106). Lincoln, NE: Buros Institute of Mental Measurement.

Lareau, A. (2003). Unequal childhoods: Class, race, and family life. Berkeley, CA: University of California Press.

Lee, J., Grigg, W., \& Dion, G. (2007). The Nation's Report Card: Mathematics 2007 (NCES 2007-494). Washington DC: National Center for Education Statistics, Institute of Education Sciences, US Department of Education.

http://nces.ed.gov/nationsreportcard/pubs/main2007/2007494.asp\#pd flist

Loveless, T. (2008). The misplaced math student: Lost in eighth-grade algebra. Washington DC: Brown Center on Education Policy at Brookings.

Majoribanks, K. (1996). Family learning environments and students outcomes: A review. Journal of Comparative Family Studies, 27, 373-394.

McCoy, L. P. (2005). Effect of demographic and personal variables on achievement in eighth-grade algebra. The Journal of Education Research, 98, 131-135. doi:10.3200/JOER.98.3.131-135
McNeal, R. B. (2001). Differential effects of parental involvement on cognitive and behavioral outcomes by socioeconomic status. Journal of Socio-Economics, 30, 171. doi:10.1016/S1053-5357(00)00100-1

Muller, C. (1998). Gender differences in parental involvement and adolescents' mathematics achievement. Sociology of Education, 71, 336356. doi: $10.2307 / 2673174$

National Association of Secondary School Principals (NASSP) (2011). Breaking down the PISA results. Newsleader, 58, 1-10.

National Council of Teachers of Mathematics (2002). Principal and standards for school mathematics. http://standardstrial.nctm.org/document/chapter6/index.htm

National Council of Teachers of Mathematics (2000). Principal and standards for school mathematics. Reston, VA: Author.

Penner, A. M. (2008). Gender difference in extreme mathematical achievement: An international perspective on biological and social factors. American Journal of Psychology, 114, S138-S170.

Räty, H., Kasanen, K., Kiiskinen, J., \& Nykky, M. (2004). Learning intelligence - Children's choices of the best pupils in the mother tongue and mathematics. Social Behavior and Personality, 32, 303312. doi: $10.2224 / \mathrm{sbp} .2004 .32 .3 .303$

Sax, L. (2010). Gender differences in learning. NASSPE Research. http://www.singlesexschools.org/research-learning.htm

Seyfried, S. F. (1998). Academic achievement of African American preadolescents: The influence of teacher perceptions. American Journal of Community Psychology, 26, 381-402. doi:10.1023/A:1022107120472

Stacey, K. (2009). Trends in mathematics education research: The example of algebra education. [Peer commentary on the study "The future of the teaching and learning of algebra" by Stacey, K., Chick, H., \& Kendal, M.] http://www.hbcse.tifr.res.in/episteme/episteme-1/epiteme-1-review-p apers/stacey

Steen, L. A. (1999). Algebra for all in eighth-grade: What's the rush? Middle Matters, 8, 6-7.

Steen, L. A. (1992). Does everyone need to study algebra. Mathematics Teacher, 85, 258-260.

Toone, L. T. (2011). Orleans-hanna algebra prognosis test: Information for students, parents, and educators. Farmington, UT: Davis School District. http://www.davis.k12.ut.us/davis

Trends in International Mathematics and Science Study (1999). Highlights from TIMSS 2007: Mathematics and science achievement of US fourth and eighth-graders in an international context. US Department of Education: National Center for Education Statistics. http://nces.ed.gov/pubsearch/pubsinfo.asp?pubid=2001027

US Department of Education (2010). Highlights from PISA 2009: Performance of US 15-year-old students in reading, mathematics, and science literacy in an international context. US Department of Education: National Center for Education Statistics http://nces.ed.gov/pubsearch/pubsinfo.asp?pubid=2011004

US Department of Education (2008). Foundations for success: The final report of the national mathematics advisory panel. http://www2.ed.gov/about/bdscomm/list/mathpanel/report/final-repor t.pdf

Valentine, E. F. (1998). Gender differences in learning and achievement in mathematics, science and technology and strategies for equity: A literature review. Psychological Foundations of Education for Pre-Service Teachers. Blacksburg, VA: Virginia Polytechnic Institute \& State University.

VanNoy, T. (2010). Teaching embedded algebra to young students. http://ezinearticles.com/?Teaching-Embedded-Algebra-to-Young-Stu dents\&id $=4771526$

Willingham, W. W., \& Cole, N. S. (1997). Gender and fair assessment. Mahwah, NJ: Lawrence Erlbaum Associates. http://www.questia.com/PM.qst?a $=$ o\&d=99105978

$\mathrm{Wu}, \mathrm{H}$. (2001). What is at stake in the K-12 standards wars: A primer for educational policy makers. The 1997 mathematics standards war in California, New York: Peter Lang Publishers. 